\title{
The relationship between sleep habits, anxiety, and depression in the elderly
}

\section{Marie-France Leblanc' Sophie Desjardins' Alain Desgagné ${ }^{2}$}

'Department of Psychology, Université du Québec à Trois-Rivières, TroisRivières, QC, Canada; ${ }^{2}$ Department of Mathematics, Université du Québec à Montréal, Montréal, QC, Canada
Correspondence: Sophie Desjardins Département de psychologie, Université du Québec à Trois-Rivières, CP 500, Trois-Rivières, QC, Canada G9A 5H7

Tel + I 819376501 I

Fax + I 8193765195

Email sophie.desjardins@uqtr.ca
This article was published in the following Dove Press journal:

Nature and Science of Sleep

5 February 2015

Number of times this article has been viewed

Purpose: The objective of this study is to determine which sleep-related behaviors are most often used by the elderly according to the presence or absence of anxiety and mood disorders. In particular, we are attempting to determine whether these behaviors are associated with the probability of suffering from a mental disorder. The behaviors being examined in the present study are taking naps, television watching or reading at bedtime, physical exercise at bedtime, relaxing activities at bedtime, and caffeine consumption in the evening.

Methods: The sample in this study consists of 2,759 participants aged 65 and over, with a mean age of 73.8. They were recruited through a method of random generation of telephone numbers according to a sampling strategy based on geographic location. After the goal of the study was explained to them, the participants agreed to have health professionals visit their home and to answer questions in an hour-and-a-half-long structured interview (after signing a consent form).

Results: Taking naps is the activity most often practiced by the elderly. Watching television and reading at bedtime are also frequent practices among them. The probabilities of suffering from anxiety are greater if the person never or rarely consumes caffeine after $6 \mathrm{pm}$, if the individual takes naps during the day, or if the person practices relaxation before bedtime. Television watching, reading, and physical exercise before bedtime are activities that are not associated with the probability of suffering from a mental disorder.

Conclusion: It would be beneficial for research to be conducted to support the findings on behavioral differences between depressive and anxious seniors so that these behaviors can become further indicators of the presence of mental disorders.

Keywords: bedtime, nap, relaxation, physical exercise, caffeine, mental health

\section{Introduction}

Many elderly people say that they sleep poorly; at least half of the seniors questioned in the USA report sleep problems, ${ }^{1,2}$ as do a similar proportion in Québec, Canada. ${ }^{3}$ The percentages recorded in Brazil are somewhat lower. ${ }^{4}$ Significant levels of anxiety and mood disorders are also found in this same age group. In Canada, the lifetime prevalence of these disorders for seniors is $10.3 \% .^{5}$ In France, approximately one older person in ten reported having one of these two types of disorders within the past month. ${ }^{6}$

Among the factors that maintain sleep difficulties are sleep-related behaviors, which have also been shown to have some associations with older individuals' mental states. ${ }^{7}$ Some of the behaviors known to affect sleep are taking naps, reading or watching television at bedtime, relaxation, coffee drinking, and physical exercise in the evening. 
Naps can thus have an impact on sleep. Taking naps becomes a popular practice as people grow older. ${ }^{7-12}$ Between the ages of 65 and 89 , the levels of nap taking increase from $15 \%$ to $50 \%$, and these levels differ significantly in individuals under 65 years of age. ${ }^{7,9}$ The number of naps also increases with age, from one nap a day to more than four on average. ${ }^{10,12,13}$ The duration of the naps becomes up to 2.5 times longer as well. ${ }^{9,10}$ Older men take more naps than older women, ${ }^{14}$ with only $10.8 \%$ of the latter taking a daily nap. ${ }^{15}$ Seniors who complain about their sleep take more frequent naps. ${ }^{15-19}$ Naps, especially when they are too long and are taken in the late afternoon, affect sleep, which then becomes shorter and of poor quality; naps also increase sleep-onset latency and awakenings. ${ }^{15,17,19-21}$ But the practice of taking naps does not allow us to systematically distinguish good sleepers from poor sleepers. ${ }^{14,22}$ For the elderly, taking short naps or naps together with moderate physical exercise early in the evening is associated with good quality sleep. ${ }^{23-25}$ Other researchers have also shown naps to have relatively little effect on sleep. ${ }^{14,22}$ Very surprisingly, not taking naps seems to be a protective factor for survival over a period of 7 years. ${ }^{11}$ Some studies have found links between naps and mental disorders, ${ }^{7}$ and particularly links to obsessive-compulsive disorder ${ }^{26}$ and depression ${ }^{15,27,28}$ in the elderly.

The second behavior that is frequently observed in this population is reading or watching television before going to bed. This is a common practice in older seniors, ${ }^{29-32}$ and the time spent watching television increases with age, to the point of doubling. ${ }^{31}$ News and sports programs are seniors' favorite television choices, followed by documentaries. ${ }^{31}$ Elderly people's beliefs have been found to be mediating variables enabling researchers to link depression and television watching ${ }^{33}$ and, more specifically, a high number of hours in front of the television and depression in older men. ${ }^{34}$ Moreover, the time spent in front of the television is negatively correlated with life satisfaction, with those who watch a great deal of television having a significantly lower level of satisfaction than those who watch television less often. ${ }^{34}$

The third behavior that can affect sleep is less popular with seniors; it is physical exercise at bedtime. The levels of practice of this activity generally diminish with age. Up to two-thirds of older persons over 75 years of age are physically inactive, but men are more active than women. ${ }^{35,36}$ Active older individuals awaken less often at night than more sedentary seniors and report longer and better quality sleep. ${ }^{37}$ Daytime physical exercise in fact tends to trigger neurochemical changes that positively influence wake-sleep cycles and the quality, quantity, and efficiency of sleep, while reducing awake time at night and daytime sleepiness. ${ }^{20,23,24,38-41}$ Physically active older people also take fewer naps, ${ }^{37}$ and the fact of practicing a physical activity seems to be a protective factor in terms of life expectancy according to a measurement performed over a 7 -year period. ${ }^{11}$ Moreover, not doing physical exercise is associated with sleep problems. ${ }^{23-25,27,40,42-44}$ The fact of seniors giving up physical activity is sometimes linked to their fear of compromising what they see as their rather precarious sleep, so that they engage in avoidance behaviors that may seem to be in accordance with their age. Canceling social, family, or work obligations, especially after having a bad night, and staying indoors all day may maintain or even increase insomia. ${ }^{40}$ The habit of exercising before bedtime, which has been observed in less than a third of the elderly, ${ }^{18,30}$ can be considered as being detrimental to sleep, especially when these physical activities are too intense. ${ }^{16,20,24,38}$ These activities lead to increased sleep-onset latency and a state of excitation that is not conducive to sleep. ${ }^{20,24,38,45}$ Daytime physical exercise can result in a lessening of psychiatric symptoms, ${ }^{40,41,46}$ and, more specifically, in a diminished depressive $\mathrm{e}^{41,47-50}$ and anxious ${ }^{48}$ symptomatology. A low level of daytime physical exercise has been associated with anxious $^{40}$ and depressive ${ }^{35}$ symptoms. Physical exercise before bedtime has been found to be linked to a greater probability of depression in raw (unadjusted) data. ${ }^{30}$

Relaxing activities at bedtime are a sleep-related behavior. They are practiced often by more than half of elderly people, ${ }^{40}$ who use them when they find it hard to fall asleep. ${ }^{16,18}$ These activities include taking a relaxing bath, listening to relaxation music or practicing gradual muscular relaxation, meditation, yoga, guided imagery, or controlled breathing. ${ }^{30,41}$ Relaxation increases sleep quality and satisfaction and decreases sleep-onset latency, nighttime awakening and daytime sleepiness. ${ }^{16,20,40,51,52}$ Relaxation before bedtime (taking a bath) was found to be linked to a greater probability of depression. ${ }^{30}$ However, relaxing activities before bedtime were also often associated with a decrease in depression and anxiety. ${ }^{48,53,54}$

The last sleep-related behavior is caffeine consumption in the evening. This habit decreases with age..$^{19,27,55,56}$ Individuals over 65 years of age consume caffeine in the form of coffee, tea, and soft drinks. ${ }^{57}$ Older people experience a stronger physiological response to caffeine, ${ }^{58}$ especially when the doses are high..$^{59,60}$ Caffeine consumption can negatively affect seniors' sleep efficiency and the duration of their sleep. ${ }^{16,27,28,40,61}$ 
The most frequent behaviors in elders struggling with insomnia are television watching, reading, taking a nap the day after a poor night's sleep, or drinking alcohol. These actions may further impair sleep. ${ }^{18}$ More women than men read to induce sleep, and the number of approaches used is proportional to the number of sleep problems. ${ }^{12,18}$ Several sleep-related behaviors have thus been studied in elderly clienteles. However, in many of these studies, the size of the sample is small, and none of the studies have examined all of the behaviors discussed in the introduction, which prevents us from measuring the actual specific link of the predictors to the mental disorders. Similarly, some of the associations that have been found between sleep-related behaviors and one or both types of mental disorders have only been observed once. This may be interesting, and it would seem relevant to try to reproduce the results, especially with a large sample. Finally, some behaviors have never been verified in terms of their direct relationship to these two types of mental disorders (television watching or reading at bedtime, for example).

The objective of this study is to determine which sleeprelated behaviors are most often used by the elderly according to the presence or absence of anxiety and mood disorders. In particular, we are attempting to determine whether these behaviors are associated with the probability of suffering from a mental disorder. The behaviors being examined in the present study are thus taking naps, television watching or reading at bedtime, physical exercise at bedtime, relaxing activities at bedtime, and caffeine consumption in the evening.

\section{Methods}

\section{Participants}

Data for this cross-sectional study were obtained from the longitudinal Quebec Survey on Seniors' Health (Enquête sur la santé des aînés) conducted during 2005-2008. ${ }^{62}$ The aim of the survey was to assess the physical and mental health of a French-speaking community-dwelling population aged over 65 in the province of Québec, Canada. The sample in this study consists of 2,759 participants aged 65 and over, with an average age of 73.8, who live in various administrative regions of Québec. They were recruited through a method of random generation of telephone numbers according to a sampling strategy based on geographic location. After the goal of the study was explained to them, the participants agreed to have health professionals visit their home and to answer the health professional's questions in an hour-and-ahalf-long structured interview (after signing a consent form).
The health professionals had been given two days of training on the computerized questionnaire. The questions that the participants were asked regarding DSM-IV-TR criteria were similar to those in the Diagnostic Interview Schedule, which has a good degree of validity and reliability. ${ }^{63}$ The questionnaire that was used was also adapted for older persons..$^{64,65}$ Sleep-related behaviors were also examined. Participants received a financial compensation of $\$ 30$. Some participants were excluded: that is, seniors with a score of less than 22 on the Mini-Mental State Examination. ${ }^{66}$ Nearly $54 \%$ of the participants reported having no spouse, and almost $65 \%$ had a secondary (or lower) level of schooling. Close to half of the participants reported having an annual income of under $\$ 25,000$. Finally, sleep efficiency (calculated by dividing the time spent sleeping by the total time spent in bed, multiplied by 100 ) was over $80 \%$ in nearly three-quarters of the elders selected for this study. Sleep efficiency was measured by noting, among other things, the number and duration of awakenings, the time taken to fall asleep, the participant's bedtime, etc.

\section{Variables}

The variables under study are connected with sleep-related behaviors, including taking a nap during the day, relaxation, television watching or reading, physical exercise - all before bedtime - and the use of caffeine after $6 \mathrm{pm}$. The participants answered the following questions: "In the past month, did you take a nap during the day?"; Before bedtime, do you "regularly practice relaxation activities (taking baths, etc)?"; "watch television or read in your bedroom?"; "do physical exercise in the two hours before going to bed?"; "drink beverages containing caffeine, after 6 pm?". The possible answers were Never, Rarely, Sometimes, Often, and Very often. These answers were divided into two categories: that is, Never or Rarely, and Sometimes to Very often. The covariables under study are sex, age (aged 75 and over, or aged 65-75), marital state (the person reports living alone or living as a couple), income (annual income over or under \$25,000), and schooling (postsecondary level or below). Sleep efficiency was also a covariable under study: the ratio of the time spent sleeping to the time spent in bed evaluated at over $80 \%$. In terms of anxiety and mood disorders, the participants were divided into three groups according to DSM-IV-TR diagnostic criteria for the disorders studied. Participants meeting the diagnostic criteria for an obsessive-compulsive disorder, a generalized anxiety disorder, a panic disorder, or a specific or social phobia were placed in the group of anxious individuals $(\mathrm{n}=103)$; participants presenting a major depression, a minor 
depression, or a mania were put in the group of depressive persons $(n=161)$; and the group of asymptomatic individuals $(n=2,495)$ consisted of participants not exhibiting a mood or anxiety disorder.

\section{Statistical analysis}

In order to evaluate the presence of differences between the three groups formed based on the diagnosis of an anxiety disorder, a mood disorder, or no mental disorder, chisquared tests were performed. These tests were conducted using PASW Statistics 18.0, with a threshold of significance set at $P<0.05$, and they included all the variables and covariables in order to obtain an overall profile of the groups under study. All the variables and covariables were used in a multinomial logistic regression analysis, and a fully adjusted model was employed. This analysis was used to assess the risk of the person presenting an anxiety or mood disorder according to the presence of one or another of the sleep-related behaviors, because it verifies the specific relationship of these predictor variables and the significant associations of each with the mental disorders under study.

\section{Results}

Naps are taken sometimes, often, or very often by $56.9 \%$ of the seniors in our sample. Watching television or reading before bedtime is also frequent in older individuals, with $53.0 \%$ of them practicing such activities sometimes, often, or very often. The levels for relaxation, caffeine consumption, and physical exercise before bedtime are $26.1 \%, 20.3 \%$, and $10.7 \%$, respectively. Table 1 presents the descriptive statistics according to the presence or absence of an anxiety or mood disorder. We find higher levels of the practicing of relaxation before bedtime for individuals dealing with

Table I Descriptive statistics for the sociodemographic variables according to the presence or absence of an anxiety or mood disorder

\begin{tabular}{|c|c|c|c|c|c|c|c|}
\hline & \multicolumn{2}{|c|}{ Asymptomatic } & \multicolumn{2}{|c|}{ Depressive } & \multicolumn{2}{|c|}{ Anxious } & \multirow[t]{2}{*}{$\chi^{2}$} \\
\hline & $\mathbf{n}$ & $\%$ & $\mathbf{n}$ & $\%$ & $\mathbf{n}$ & $\%$ & \\
\hline \multicolumn{8}{|l|}{ Nap during the day } \\
\hline Never or rarely & I,087 & 43.6 & 67 & 41.6 & 34 & 33 & \\
\hline Sometimes to very often & 1,406 & 56.4 & 94 & 58.4 & 69 & 67 & \\
\hline Relaxation before bedtime & & & & & & & $* *$ \\
\hline Never or rarely & $\mathrm{I}, 865$ & 75 & 106 & 65.8 & 62 & 60.8 & \\
\hline Sometimes to very often & 623 & 25 & 55 & 34.2 & 40 & 39.2 & \\
\hline \multicolumn{8}{|l|}{$\mathrm{TV}$ or reading before bedtime } \\
\hline Never or rarely & $\mathrm{I}, 160$ & 46.6 & 79 & 48.8 & 53 & 52 & \\
\hline Sometimes to very often & $\mathrm{I}, 327$ & 53.4 & 83 & 51.2 & 49 & 48 & \\
\hline \multicolumn{8}{|l|}{ Exercise before bedtime } \\
\hline Never or rarely & 2,227 & 89.6 & 136 & 84.5 & 92 & 89.3 & \\
\hline Sometimes to very often & 258 & 10.4 & 25 & 15.5 & II & 10.7 & \\
\hline \multicolumn{8}{|l|}{ Caffeine after 6 pm } \\
\hline Never or rarely & $\mathrm{I}, 974$ & 79.4 & 128 & 79.5 & 90 & 87.4 & \\
\hline Sometimes to very often & $5 I I$ & 20.6 & 33 & 20.5 & 13 & 12.6 & \\
\hline Age & & & & & & & $*$ \\
\hline Under 75 & $\mathrm{I}, 430$ & 57.3 & 107 & 66.5 & 65 & 63.7 & \\
\hline 75 and over & $\mathrm{I}, 064$ & 42.7 & 54 & 33.5 & 37 & 36.3 & \\
\hline Sex & & & & & & & ** \\
\hline Male & I,057 & 42.4 & 46 & 28.6 & 29 & 28.4 & \\
\hline Female & 1,438 & 57.6 & 115 & 71.4 & 73 & 71.6 & \\
\hline \multicolumn{8}{|l|}{ Civil status } \\
\hline Married or living together & $\mathrm{I}, \mathrm{I} 50$ & 46.3 & 70 & 44 & 50 & 49.5 & \\
\hline Single, separated, divorced, or widowed & 1,336 & 53.7 & 83 & 56 & 51 & 50.5 & \\
\hline \multicolumn{8}{|l|}{ Schooling } \\
\hline None to secondary & 1,618 & 64.9 & 108 & 67.1 & 58 & 56.3 & \\
\hline Postsecondary & 876 & 35.1 & 53 & 32.9 & 45 & 43.7 & \\
\hline \multicolumn{8}{|l|}{ Annual household income } \\
\hline Under $\$ 25,000$ & 1,229 & 49.3 & 77 & 47.5 & 51 & 49.5 & \\
\hline$\$ 25,000$ and over & $\mathrm{I}, 264$ & 50.7 & 85 & 52.5 & 52 & 50.5 & \\
\hline Sleep efficiency & & & & & & & $*$ \\
\hline $80 \%$ or more & $\mathrm{I}, 624$ & 72.5 & 94 & 65.3 & 56 & 61.5 & \\
\hline Less than $80 \%$ & 617 & 27.5 & 50 & 34.7 & 35 & 38.5 & \\
\hline
\end{tabular}

Note: $* P<0.05 ; * * P<0.01$. 
depression or anxiety than for those not suffering from any disorder. Anxious persons exhibit the highest levels of practice of relaxation techniques. Only a quarter of asymptomatic older people practice this activity, whereas more than a third of anxious and depressive seniors habitually do so. Compared with asymptomatic older individuals, depressive or anxious elders do not show any significant difference in terms of television watching, reading, and physical exercise before bedtime. Taking naps is popular with anxious persons, two-thirds of whom do so. We find that women and younger seniors (under 75 years of age) are overrepresented in the depressive and anxious groups, compared with the group of those not suffering from any mental disorder. Sleep efficiency is more often under $80 \%$ for depressive and anxious older persons than for asymptomatic elders.
The results of the regression analysis (Table 2) show that the probabilities of suffering from anxiety are greater if the person never or rarely consumes caffeine after $6 \mathrm{pm}$, if the individual takes naps during the day, or if the person practices relaxation before bedtime. Compared with asymptomatic individuals, television watching, reading, and physical exercise before bedtime are activities that are not associated with the probability of suffering from a mental disorder. The specific effect of each variable is taken into account only once, despite the fact that both anxiety and mood disorders show higher levels for the practicing of relaxation, only the risk of anxiety is associated with this practice. The practice of relaxation thus clearly shares a common variance with other variables, and once we have controlled for this effect, the direct link with mood disorders is no longer visible.

Table 2 Odds ratios $(\mathrm{OR})$ and confidence intervals $(\mathrm{Cl})$ for sleep-related behaviors predicting the presence or absence of an anxiety or mood disorder

\begin{tabular}{|c|c|c|c|c|c|c|}
\hline & \multicolumn{2}{|c|}{$\begin{array}{l}\text { Depressive vs } \\
\text { asymptomatic }^{\mathrm{a}}\end{array}$} & \multicolumn{2}{|c|}{$\begin{array}{l}\text { Anxious vs } \\
\text { asymptomatic }^{\mathrm{a}}\end{array}$} & \multicolumn{2}{|c|}{$\begin{array}{l}\text { Depressive vs } \\
\text { anxious }^{\text {a }}\end{array}$} \\
\hline & $\overline{\text { OR }}$ & $95 \% \mathrm{Cl}$ & $\overline{\text { OR }}$ & $95 \% \mathrm{Cl}$ & $\overline{\text { OR }}$ & $95 \% \mathrm{Cl}$ \\
\hline \multicolumn{7}{|l|}{ Nap during the day } \\
\hline Never or rarely & 0.88 & $0.62-1.24$ & $0.48^{* *}$ & $0.30-0.77$ & 1.82 & $1.03-3.23$ \\
\hline Sometimes to very often & 1 & & 1 & & 1 & \\
\hline \multicolumn{7}{|l|}{ Relaxation before bedtime } \\
\hline Never or rarely & 0.73 & $0.50-1.06$ & $0.5 I^{* *}$ & $0.33-0.81$ & 1.42 & $0.80-2.50$ \\
\hline Sometimes to very often & 1 & & I & & 1 & \\
\hline \multicolumn{7}{|l|}{ TV or reading before bedtime } \\
\hline Never or rarely & 1.27 & $0.90-1.79$ & 1.5 & $0.97-2.32$ & 0.84 & $0.49-1.45$ \\
\hline Sometimes to very often & 1 & & I & & I & \\
\hline \multicolumn{7}{|l|}{ Exercise before bedtime } \\
\hline Never or rarely & 0.68 & $0.42-1.14$ & 1.39 & $0.65-2.95$ & 0.49 & $0.20-1.18$ \\
\hline Sometimes to very often & 1 & & I & & 1 & \\
\hline \multicolumn{7}{|l|}{ Caffeine after 6 pm } \\
\hline Never or rarely & 0.96 & $0.63-1.47$ & $2.24^{*}$ & I.1I-4.52 & $0.43 *$ & $0.19-0.96$ \\
\hline Sometimes to very often & 1 & & I & & 1 & \\
\hline \multicolumn{7}{|l|}{ Age } \\
\hline Under 75 & $1.74 * *$ & $1.19-2.53$ & 1.26 & $0.80-1.98$ & 1.38 & $0.78-2.46$ \\
\hline 75 and over & I & & I & & 1 & \\
\hline \multicolumn{7}{|l|}{ Sex } \\
\hline Male & $0.48^{* *}$ & $0.32-0.73$ & $0.60^{*}$ & $0.36-0.98$ & 0.81 & $0.43-1.53$ \\
\hline Female & I & & I & & I & \\
\hline \multicolumn{7}{|l|}{ Civil status } \\
\hline Married or living together & 0.76 & $0.52-1.12$ & 1.31 & $0.82-2.10$ & 0.58 & $0.32-1.05$ \\
\hline Single, separated, divorced, or widowed & 1 & & I & & 1 & \\
\hline \multicolumn{7}{|l|}{ Schooling } \\
\hline None to secondary & 1.18 & $0.80-1.75$ & $0.59 *$ & $0.37-0.94$ & $2.00 *$ & $1.11-3.6 \mid$ \\
\hline Postsecondary & I & & I & & 1 & \\
\hline \multicolumn{7}{|l|}{ Annual household income } \\
\hline Under $\$ 25,000$ & 0.7 & $0.47-1.03$ & 1.04 & $0.64-1.70$ & 0.67 & $0.36-1.23$ \\
\hline$\$ 25,000$ and over & I & & I & & 1 & \\
\hline \multicolumn{7}{|l|}{ Sleep efficiency } \\
\hline $80 \%$ or more & 0.75 & $0.52-1.07$ & 0.67 & $0.42-1.04$ & 1.12 & $0.64-1.97$ \\
\hline Less than $80 \%$ & I & & I & & I & \\
\hline
\end{tabular}

Notes: ${ }^{R}$ Reference group. $R^{2}=0.03$ I (Cox and Snell), 0.059 (Nagelkerke). Model $\chi^{2}(22)=78.20, P<0.001$. $* P<0.05, * * P<0.01$. 
To conclude, in terms of classification, we obtained a percentage of accuracy of $90.6 \%$. Nor was any multicollinearity detected, according to the statistical tolerance levels obtained, which were higher than 0.20 .

\section{Discussion}

The first part of the objective targeted by this study was to identify the sleep-related behaviors performed by the elderly according to the presence or absence of an anxiety or mood disorder. When we examine each of these behaviors, we find that taking naps is the activity most often practiced. Naps are indeed popular with the seniors in this sample, which is in line with the literature on this topic. ${ }^{8-12}$ Watching television and reading at bedtime are also frequent practices among older seniors. These are the most common of the five behaviors investigated, which also concurs with the findings in the literature. ${ }^{12,18,29-32}$ Relaxation at bedtime shows lower levels of practice than those found in the literature. ${ }^{40}$ Caffeine consumption diminishes with age, ${ }^{19,27,55,56}$ so that we see that a low level of the elderly (in all of the groups combined) consume it in the evening. Finally, the seniors show a low level of practicing physical exercise in the evening, one that is lower than that reported in the literature. ${ }^{35,36}$

The second part of the objective was to determine whether these behaviors are associated with the probability of suffering from a mental disorder. We know that several sleep-related behaviors are associated with the elderly's mental state, but that not all sleep-related behaviors show significant differences in the three groups, once we have controlled for the other variables. Thus, once we have controlled for the other sleep-related behaviors and the sociodemographic variables under study, three behaviors show significant results and can be considered as predictive factors for the presence of a mental disorder. As we mentioned earlier, relaxation, naps, and not using caffeine stand out as factors that can predict the person's belonging to the anxious group.

As our findings show, seniors in the three groups are inclined to take naps; more than half of the participants in fact report that they take a nap. What we also know about naps is that developmental changes related to sleep that occur in asymptomatic elderly individuals can foster the popularity of this sleep habit: the need for sleep arises earlier and sleep is lighter, for example. ${ }^{67}$ These factors may reinforce people's desire to catch up on sleep during the day. Anxious individuals also try to act against the perceived potential threat associated with their sleep being affected by this mental disorder, in order to compensate for the lost hours of sleep. This attitude, focusing on prevention and control, also seems to be consistent with the state of mind of many anxious persons. Naps are frequent in anxious seniors, and is associated with belonging to the group of individuals dealing with an anxiety disorder. These individuals tend to unconsciously avoid mental images and negative feelings and sensations associated with the perceived danger. ${ }^{68}$ Taking naps may represent a break: a way of putting their concerns, fears, and worries aside. ${ }^{69}$ Taking naps is not associated with the probability of suffering from a mood disorder, despite the fact that such a link has been found in the literature. ${ }^{15,27,28}$ Some authors ${ }^{70}$ have explored the probabilities of depressive persons taking more naps by measuring the number and duration of the naps. We can thus imagine that the association between naps and depression involves changes in sleep such as excessive daytime sleepiness or insomnia, which are frequent manifestations in depressive persons that may induce them to sleep during the day. So, only one short daily nap may not be associated with the probability of having a mood disorder, because the impact of the nap is minimal if it is brief. The fact of not measuring the duration of the nap may have an impact on the results obtained. The way that the questions were formulated in this study does not allow us to distinguish people who take many long naps from those who only take one short nap. The same is true for the time at which naps are taken and for the number of days, within a given period, when naps are taken.

In terms of physical exercise before bedtime in older individuals, the practice levels were low in this case. A minimal practice level could be associated with depressive symptoms, ${ }^{35}$ as the symptomatology includes loss of interest and great fatigue, so that fatigued elderly persons may possibly not feel the need to make themselves even more tired. In fact, doing exercises before bedtime was not found to be different in elders struggling with an anxiety or mood disorder. So the link between exercise at bedtime and mental disorders could simply be due to sleep problems. Indeed, exercises that are too intense are associated with increased sleep-onset latency, which may play a part in the vicious circle of frequent sleep problems in both anxious and depressive individuals. In this study, the type of physical exercises and their duration and intensity were not measured, and the association between this practice and the mental disorders may perhaps be based on these elements. Moreover, studies have more often measured the practicing of daytime physical exercises, unlike the present study, which specifies that this exercise takes place at bedtime, thus modifying the methodological conditions of studies that found associations with depression ${ }^{41,46-50}$ or anxiety. ${ }^{40,48}$ 
A number of studies discuss the various mental health benefits of a relaxation practice,,$^{40,48,53,54}$ including, more specifically, a reduction in depression and anxiety. ${ }^{48,53,54}$ Relaxation enabled us to distinguish the groups formed according to the presence or absence of a mental disorder, and older participants suffering from a mental disorder show the highest practice levels, particularly anxious individuals. We know the cognitive processes present in anxiety disorders: hypervigilance, neurovegetative hyperactivity, and a state of tension. ${ }^{69}$ These elements represent a major motivation for a relaxation practice. We can hypothesize that anxious persons naturally tend to focus on this natural method, which is primarily targeted to stress and anxiety. ${ }^{71}$ Seniors affected by this mental disorder may also perform this activity ineffectively. ${ }^{72}$ So it would be beneficial if the therapeutic goals of relaxation were supported by a practice supervised by welltrained practitioners. Relaxation requires some training and some mastery. People trying to practice relaxing activities at bedtime without such support may become more stressed and thereby increase their anxiety. Finally, anxious older individuals who notice a gradual change in their state of health and living situation may want to increase their sense of power and control. ${ }^{68}$ On the other hand, the mental disposition of depressive persons tends toward apathy, loss of interest, and hypersomnia, and less toward emphasizing proactive means of improving their mood or their sleep, such as relaxation. We may thus presume that they do not feel the same need to relax and prepare for sleep that anxious persons do. Our results are in line with this: relaxing at bedtime is not associated with the probability of being affected by a mood disorder.

Watching television and reading before bedtime are popular with both asymptomatic elderly individuals and seniors dealing with a mental disorder. These behaviors do not show a link to the presence of a mental disorder, although older men struggling with a mental disorder often watch television for a greater number of hours than those without a mental disorder. ${ }^{34}$ We know, however, that certain maladaptive cognitions associated with the two types of mental disorders may influence the mental availability needed for these activities: concerns, fearful expectations, and excessive worries in the case of anxiety, or general psychic asthenia and lack of motivation in the case of depression. ${ }^{68,69,73}$ So, although asymptomatic elderly individuals may be more willing and able to practice these two types of activities in theory, our data do not tend to show this. The differences may perhaps be based on the type of reading or television shows watched: televised news, which is often during bedtime hours, may exacerbate a negative mood or anxiety, for example. Because the characteristics of these practices were not explored, we cannot presume the influence of these practices proportionally to the effective duration of watching television or reading, or to the type of shows or reading chosen. It would indeed appear useful, for both prevention and intervention, to verify the possible relationship between these two practices and the presence of an anxiety or mood disorder. A cross-sectional study cannot establish a causal link, which is why these two behaviors could be seen as either a possible cause, or a consequence, of the presence of these two types of disorders.

The link between the popular stimulant, caffeine, and the mental disorders differs according to the mental disorder. The low consumption found could lead one to believe that seniors fear that coffee will impair their sleep and simply just avoid consuming it, which is in keeping with an adjustment to the developmental changes in their metabolism. We in fact find that only one in five older individuals drinks coffee in the evening. We can also hypothesize that elders report little caffeine use because they strongly underestimate their consumption; the presence of caffeine in medication and/or food often goes unnoticed. ${ }^{27,40}$ It is found in a number of foods, beverages, and medications, including soft drinks, chocolate, analgesics, steroids, bronchodilators, high-blood pressure medication, and decongestants. ${ }^{20,21,38}$ Perhaps future studies can provide participants with a table or picture of caffeine content in different foods or beverages for a reference. The low levels of consumption may also be related to the fact that seniors know that they are sensitive to this stimulant. ${ }^{58-60} \mathrm{We}$ can hypothesize that older individuals dealing with a mood disorder tend to use this stimulant more to counter the decline in their energy and their fatigue. We find that caffeine consumption after $6 \mathrm{pm}$ is indeed more strongly associated with the probability of suffering from depression rather than anxiety. Anxious older persons appear to avoid caffeine, which can indeed aggravate anxiety. ${ }^{74}$ In this regard, we in fact see that caffeine abstention is associated with the probability of struggling with an anxiety disorder. No studies were found concerning seniors' caffeine consumption after 6 $\mathrm{pm}$, regardless of whether they were affected by a mental disorder. The tendency of anxious individuals to avoid caffeine has been confirmed only in adults under 65 years of age. ${ }^{75}$ Some researchers have indeed associated caffeine use with anxiety, and low caffeine consumption is in fact linked to a greater probability of suffering from anxiety in adults ${ }^{76,77}$ So verifications involving an elderly clientele add some interesting specifications in this regard. 


\section{Conclusion}

The relationship of the various sleep-related behaviors to mental disorders in the elderly has been little studied, and the aim of the present study is to add to the knowledge held in this respect. This study is of interest in that, among other things, it involves a large sample of more than 2,000 participants, which is of random composition. The data come from structured interviews, which foster the validity of the information gathered. The characteristics of this sample are limited to the elderly population, but are comparable to those of the general population in Québec. Men and elders over 75 years of age are not underrepresented, and younger seniors have been differentiated from older ones, in accordance with the recommendations in the literature on this topic. ${ }^{78}$ In terms of recommendations, a more accurate measurement and verification of the actual caffeine consumption would appear to be relevant, as this consumption could have sizeable impacts and be strongly underestimated. It would also seem advisable to specify the type of television shows viewed before bedtime and to separate the practice of bedtime reading from that of watching television. It would be helpful to verify the practicing of physical exercise during the day as well, and to measure, in number of minutes, the time slept during naps. It would also be interesting to take into account the time at which naps are taken, and the seniors' actual bedtime. Finally, there should be more details on the practicing of relaxing activities at bedtime, whether in terms of support and guidance or the type of activities practiced. This crosssectional study does not enable one to assign causality to the variables. Conducting future studies using an experimental or quasi-experimental design will allow for more in-depth exploration of the significant associations found in the present study and will enable the elements mentioned earlier to be taken into account. And it is only at this point that clinical recommendations can be made.

This study has a number of clinical implications. To our knowledge, no other study has had as its topic of study of the systematic verification of the relations between sleeprelated behaviors and anxiety and mood disorders in the elderly, the present results will therefore contribute to the knowledge on this subject. Also, the link found between certain sleep-related behaviors and mental disorders reminds us of the importance of treating these disorders as soon as they are detected so as to avoid having the elderly fall into a vicious circle of behaviors affecting sleep and mental disorders, and vice versa. It would be beneficial for research to be conducted to support the findings on behavioral differences between depressive and anxious seniors so that these behaviors can become further indicators of the presence of mental disorders. Several studies have observed the major repercussions of sleep hygiene on insomnia ${ }^{14,20,40,79,80}$ and mood, ${ }^{51}$ and in this regard, the specific effect of naps, caffeine, and relaxation is linked to the risk of suffering from anxiety. It is interesting to note that naps have not been related to mood disorders. We know that excessive daytime sleepiness is a symptom associated with mood disorders in the DSM-IV-TR. Thus, according to the present results, naps are not a manifestation of this hypersomnia in the group dealing with a mood disorder. This distinction allows us to add to the state of knowledge in regard to the expression of mood disorders. Despite the fact that it is often recommended that one limit the time spent in bed to sexual activities or sleep, in order to avoid intellectual stimulation that may impair sleep, ${ }^{20,21,27}$ the present study does not support any relationship between a stimulating activity and anxiety disorders. On the contrary, not drinking coffee in the evening and the practicing a relaxing activity have both been found to be related to anxiety disorders. This piece of data does not support the positive action generally associated with cognitive-behavioral therapy targeted to sleep habits for chronic insomnia. ${ }^{81} \mathrm{As}$ already mentioned, it would be premature and risky to use the findings discussed earlier as a basis for making clinical recommendations. For example, drinking coffee in the evening and not practicing a relaxing activity at bedtime to protect against a potential mental health problem would represent an erroneous interpretation and an improper use of the results obtained in the present study.

\section{Acknowledgments}

This research was supported by the Fonds de recherche en santé du Québec. The authors would like to thank the research group from the Quebec Survey on Seniors' Health (Enquête sur la santé des aînés) study and Michel Préville for the acquisition of funding and the collection of data.

\section{Disclosure}

The authors report no conflicts of interest in this work.

\section{References}

1. Foley DJ, Monjan AA, Brown SL, Simonsick EM, Wallace RB, Blazer DG. Sleep complaints among elderly persons: an epidemiologic study of three communities. J Sleep Res. 1995;18:425-432.

2. McCall WV. Diagnosis and management of insomnia in older people. Prim Care Companion J Clin Psychiatry. 2004;6:9-20. 
3. Béland SG, Préville M, Dubois MF; Scientific Committee of the ESA Study, et al. The association between length of benzodiazepine use and sleep quality in older population. Int J Geriatr Psychiatry. 2011;26: 908-915.

4. Blay SL, Andreoli SB, Gastal FL. Prevalence of self-reported sleep disturbance among older adults and the association of disturbed sleep with service demand and medical conditions. Int Psychogeriatr. 2008;20:582-595.

5. Statistique Canada. Enquête sur la santé dans les collectivités canadiennes (ESCC). Santé mentale et bien-être; 2003. Available from: http://www.statcan.gc.ca/pub/82-617-x/index-fra.htm.

6. Bellamy V, Roelandt J-L, Caria A. Troubles mentaux et représentations de la santé mentale: premiers résultats de l'enquête Santé mentale en population générale [Mental disorders and mental health representations' first results of the French general population study on mental health]. Études et résultats. 2004;347:1-12. French.

7. Ohayon MM, Zulley J, Guilleminault C, Smirne S, Priest RG. How age and daytime activities are related to insomnia in the general population consequences for older people. J Am Geriatr Soc. 2001;49:360-366.

8. Cohen-Mansfield J, Jensen B. Sleep-related habits and preferences in older adults: a pilot study of their range and self-rated importance. Behav Sleep Med. 2005;3:209-226.

9. Park YM, Matsumoto K, Jin Seo Y, Jeung Kang M, Nagashima H. Change of sleep or waking habits by age and sex in Japanese. Percept Mot Skills. 2002;94:1199-1213.

10. Park YM, Matsumoto K, Jin Seo Y, Jeung Kang M, Nagashima H. Effects of age and gender on sleep habits and sleep trouble for aged people. Biol Rhythm Res. 2002;33:39-51.

11. Stessman J, Hammerman-Rozenberg R, Maaravi Y, Azoulai D, Cohen A. Strategies to enhance longevity and independent function: the Jerusalem longitudinal study. Mech Ageing Dev. 2005; 126:327-331.

12. Zilli I, Ficca G, Salzarulo P. Factors involved in sleep satisfaction in the elderly. Sleep Med. 2009;10:233-239.

13. Huang Y-L, Liu R-Y, Wang Q-S, Van Someren EJW, Xu H, Zhou J-N Age-associated difference in circadian sleep-wake and rest-activity rhythms. Physiol Behav. 2002;76:597-603.

14. Alapin I. The Role of Nocturnal Cognitive Arousal in the Complaint of Insomnia Among Older Adults [unpublished doctoral dissertation] Concordia University; 2000. Available from: http://search.proquest. com.biblioproxy.uqtr.ca/docview/304625208/fulltextPDF/14118B7E CBB29453201/1?accountid=14725.

15. Stone KL, Ewing SK, Ancoli-Israel S, et al. Self-reported sleep and nap habits and risk of mortality in a large cohort of older women. $J \mathrm{Am}$ Geriatr Soc. 2009;57:604-611.

16. Gauriau C, Raffray T, Choudat D, Corman B, Léger D. Les troubles du sommeil peuvent être objectivement améliorés chez les seniors par un programme personnalisé d'éducation à la santé [Objective improvement of sleep disorders in the elderly by a health education program]. Presse Med. 2007;36:1721-1731. French

17. Goldman SE, Hall M, Boudreau R, et al. Association between nighttime sleep and napping in older adults. Sleep. 2008;31:733-740.

18. Gooneratne NS, Tavaria A, Patel N, et al. Perceived effectiveness of diverse sleep treatments in older adults. J Am Geriatr Soc. 2011; 59:297-303.

19. McCrae CS, Rowe MA, Dautovich ND, et al. Sleep hygiene practices in two community dwelling samples of older adults. Sleep. 2006;29: 1551-1560.

20. Beaulieu P. Traitement cognitivo-comportemental de l'insomnie chronique [unpublished doctoral dissertation]. Val-de-Marne University; 2006. Available from: http://doxa.u-pec.fr/theses/th0243099.pdf.

21. Bloom HG, Ahmed I, Alessi CA, et al. Evidence-based recommendations for the assessment and management of sleep disorders in older persons. J Am Geriatr Soc. 2009;57:761-789.

22. Dautovich ND, McCrae CS, Rowe MA. Subjective and objective napping and sleep in older adults: are evening naps "bad" for nighttime sleep? J Am Geriatr Soc. 2008;56:1681-1686.
23. Tanaka H, Taira K, Arakawa M, et al. Effects of short nap and exercise on elderly people having difficulty in sleeping. Psychiatry Clin Neurosci. 2001;55:173-174.

24. Tanaka H, Taira K, Arakawa M, et al. Short naps and exercise improve sleep quality and mental health in the elderly. Psychiatry Clin Neurosci. 2002;56:233-234.

25. Uezu E, Taira K, Tanaka H, et al. Survey of sleep-health and lifestyle of the elderly in Okinawa. Psychiatry Clin Neurosci. 2000;54:311-313.

26. Frisoni GB, de Leo D, Rozzini R, Trabucchi M. Napping in the elderly and its association with night sleep and psychological status. Psychogeriatry. 1996;8:477-487.

27. Almeida OP, Tamai S, Garrido R. Sleep complaints among the elderly: results from a survey in a psychogeriatric outpatient clinic in Brazil Int Psychogeriatr. 1999;11:47-56.

28. Ohayon MM. Interactions between sleep normative data and sociocultural characteristics in the elderly. $J$ Psychosom Res. 2004;56:479-486.

29. Clark BK, Sugiyama T, Healy GN, et al. Socio-demographic correlates of prolonged television viewing time in Australian men and women: the AusDiab study. J Phys Act Health. 2010;7:595-601.

30. Furihata R, Uchiyama M, Takahashi S, et al. Self-help behaviors for sleep and depression: a Japanese nationwide general population survey. J Affect Disord. 2011;130:75-82.

31. Gibbons R. Reflections in the Glass: Television and the Elderly [unpublished doctoral dissertation]. Toronto University; 2003. Available from: http://search.proquest.com.biblio proxy.uqtr.ca/docview/305256013/ fulltextPDF/14118C93B8A3B377580/1? accountid=14725.

32. Mares M-L, Woodard EH 4th. In search of the older audience: adult age differences in television viewing. $J$ Broadcast Electron Media. 2006;50:595-614.

33. Nguyen GT, Wittink MN, Murray GF, Barg FK. More than just a communication medium: what older adults say about television and depression. Gerontologist. 2008;48:300-310.

34. Murren MA. Television Viewing and Older Adults: the Effects of Active Viewing, Passive Viewing, and Viewing Type [unpublished doctoral dissertation]. Université de La Verne; 2010. Available from: http://search. proquest.com.biblioproxy.uqtr.ca/docview/849307993/fulltextPDF/14 118CF4AE2A4FC019/1? accountid=14725.

35. Lampinen P, Heikkinen R-L, Ruoppila I. Changes in intensity of physical exercise as predictors of depressive symptoms among older adults: an eight-year follow-up. Prev Med. 2000;30:371-380.

36. Statistique Canada. Dépression. Rapport statistique sur la santé de la population canadienne, Ottawa; 1999.

37. Guimaraes LHCT, Carvalho LBC, Yanaguibashi G, do Prado GF. Physically active elderly women sleep more and better than sedentary women. Sleep Med. 2008;9:488-493.

38. Epstein DR. A Behavioral Intervention to Enhance the Sleep-Wake Patterns of Older Adults with Insomnia [unpublished doctoral dissertation]. University of Arizona; 1994. Available from: http://search. proquest.com.biblioproxy.uqtr.ca/docview/304085578/fulltextPDF/14 118BEE794C994E81/1?accountid=14725.

39. Gruau S, Pottier A, Davenne D, Denise P. Les facteurs d'accidents de la route par somnolence chez les conducteurs âgés: prévention par l'activité physique [Sleepiness-related road traffic accidents among elderly drivers: an analysis of the contributory factors: The preventive role of physical activity]. Recherche-Transports-Sécurité. 2003; 7(9-80):134-144. French.

40. MacLeod MAK. Attitudes and Beliefs about Insomnia Treatment Among Older Adults with Chronic Insomnia [unpublished doctoral dissertation]. Calgary University; 2000. Available from: http://search.proquest.com. biblioproxy.uqtr.ca/docview/304589448/fulltext PDF/141188B00C33 D75DE18/1?accountid=14725.

41. Singh NA, Clements KM, Fiatarone MA. A randomized controlled trial of the effect of exercise on sleep. Sleep. 1997;20:95-101.

42. Foley DJ, Ancoli-Israel S, Britz P, Walsh J. Sleep disturbances and chronic disease in older adults: results of the 2003 national sleep foundation sleep in America survey. J Psychosom Res. 2004; $56: 497-502$ 
43. Tjepkema M. Insomnie. Rapports sur la santé/Statistique Canada, Centre canadien d'information sur la santé, 2005;17:9-25. Available from: http://web.ebscohost.com.

44. Turcotte M, Schellenberg G. Un portrait des aînés au Canada. Statistique Canada, Division de la statistique sociale et autochtone. Ministère de 1'Industrie; 2006. Available from: http://www.statcan.gc.ca/pub/89-519 -x/89-519-x2006001-fra.pdf.

45. Espie CA. Insomnia: conceptual issues in the development, persistence, and treatment of sleep disorder in adults. Annu Rev Psychol. 2002;53: 215-243.

46. Reid KJ, Baron KG, Lu B, Naylor E, Wolfe L, Zee PC. Aerobic exercise improves self-reported sleep and quality of life in older adults with insomnia. Sleep Med. 2010;11:934-940.

47. Herman S, Blumenthal JA, Babyak M, et al. Exercise therapy for depression in middle-aged and older adults: predictors of early drop out and treatment failure. Health Psychol. 2002;21:553-563.

48. Johansson M, Hassmén P, Jouper J. Acute effects of qigong exercise on mood and anxiety. Sport Exerc Perform Psychol. 2011;1:60-65.

49. Ku P-W, Fox KR, Chen L-J, Chou P. Physical activity and depressive symptoms in older adults: 11-year follow-up. Am J Prev Med. 2012;42: 355-362.

50. Lee LK, Shahar S, Chin A-V. Predicting comorbidities, nutritional status, and neuropsychological performance of depressed and nondepressed geriatric communities: a comparative study. Int J Gerontol. 2012;6:278-284.

51. Chen P-J. The Influence of Participant-Selected Versus ExperimenterChosen Music on Subjective Sleep Quality of People Over 60 Years of Age [unpublished doctoral dissertation]. Michigan State University; 2008. Available from: http://search.proquest.com.biblioproxy. uqtr.ca/ docview/304577788/fulltextPDF/14118BA6D5B5D539B96/1?accou ntid= 14725 .

52. Johnson JE. Progressive relaxation and the sleep of older noninstitutionalized women. Appl Nursing Res. 1991;4:165-170.

53. Chen KM, Chen MH, Chao HC, Hung HM, Lin HS, Li CH. Sleep quality, depression state, and health status of older adults after silver yoga exercises: cluster randomized trial. Int J Nurs Stud. 2009;46:154-163.

54. DeBerry S. The effects of meditation-relaxation on anxiety and depression in a geriatric population. Psychotherapy (Chic). 1982;19:512-521.

55. Hogervorst E, Riedel WJ, Schmitt JAJ, Jolles J. Caffeine improves memory performance during distraction in middle-aged, but not in young or old subjects. Hum Psychopharmacol. 1998;13:277-284.

56. van Boxtel MPJ, Schmitt JAJ, Bosma H, Jolles J. The effects of habitual caffeine use on cognitive change: a longitudinal perspective. Pharmacol Biochem Behav. 2003;75:921-927.

57. Frary CD, Johnson RK, Wang MQ. Food sources and intakes of caffeine in the diets of persons in the United States. J Am Diet Assoc. 2005;105: $110-113$.

58. Arciero PJ, Gardner AW, Benowitz NL, Poehlman ET. Relationship of blood pressure, heart rate and behavioral mood state to norepinephrine kinetics in younger and older men following caffeine ingestion. Eur $J$ Clin Nutr. 1998;52:805-812.

59. Massey LK. Caffeine and the elderly. Drugs Aging. 1998;13:43-50.

60. Swift CG, Tiplady B. The effects of age on the response to caffeine. Psychopharmacology. 1988;94:29-31.

61. Carrier J, Paquet J, Fernandez-Bolanos M, et al. Effects of caffeine on daytime recovery sleep: a double challenge to the sleep-wake cycle in aging. Sleep Med. 2009;10:1016-1024.

Nature and Science of Sleep

\section{Publish your work in this journal}

Nature and Science of Sleep is an international, peer-reviewed, open access journal covering all aspects of sleep science and sleep medicine, including the neurophysiology and functions of sleep, the genetics of sleep, sleep and society, biological rhythms, dreaming, sleep disorders and therapy, and strategies to optimize healthy sleep. The journal welcomes
62. Préville M, Boyer R, Grenier S, et al; Scientific Committee of the ESA Study. The epidemiology of psychiatric disorders in the Quebec older adult population. Can J Psychiatry. 2008;53:822-832.

63. Robins LN, Heizer JE, Croughan J, Rathcliff KS. National Institute of Mental Health Diagnostic Interview Schedule. Its history, characteristics, and validity. Arch Gen Psychiatry. 1981;38:381-389.

64. Adam A-M. Difficultés subjectives de sommeil chez les personnes âgées présentant ou non un trouble cognitif sans démence [unpublished doctoral dissertation]. Laval University; 2013. Available from: http:// www.theses.ulaval.ca/2013/29698/29698.pdf.

65. Préville M, Boyer R, Vasiliadis HM, et al; Scientific Committee of the ESA Study. One-year incidence of psychiatric disorders in Quebec's older adult population. Can J Psychiatry. 2010;55:449-457.

66. Folstein MF, Folstein SE, McHugh PR. Mini-mental state: a practical method for grading the cognitive state of patients for the clinician. J Psychiatr Res. 1975;12:189-198.

67. Beck-Little R. Sleep Enhancement Interventions and the Sleep of Institutionalized Older Adults [unpublished doctoral dissertation]. University of South Carolina; 2000. Available from: http://search.proquest. com.biblioproxy.uqtr.ca/docview/304621638/fulltext PDF/141187BF5 774700 F0B4/1? accountid=14725.

68. Barlow DH, Durand VM. Psychopathologie: Une Perspective Multidimensionnelle. 2nd ed. Paris: De Boeck Université; 2004.

69. American Psychiatric Association. DSM-IV-TR, Manuel Diagnostique des Troubles Mentaux. 4th ed. Paris: Masson; 2000.

70. Maglione JE, Ancoli-Israel S, Peters KW, et al. Depressive symptoms and subjective and objective sleep in community-dwelling older women. $J$ Am Geriatric Soc. 2012;60:635-643.

71. Lupien S. Le stress sans détresse; 2011. Available from: http://www. sonialupien.com.

72. Hofmann SG, Schulz SM, Heering S, Muench F, Bufka LF. Psychophysiological correlates of generalized anxiety disorder with or without comorbid depression. Int J Psychophysiol. 2010;78:35-41.

73. Lalonde P, Aubut J, Grunberg F, et al. Psychiatrie clinique, Une Approche Bio-Psycho-Sociale (Tome I). Québec: Gaétan Morin; 1999.

74. Smith A. Effects of caffeine on human behavior. Food Chem Toxicol. 2002;40:1243-1255.

75. Rogers PJ, Heatherley SV, Mullings EL, Wu Y, Leonards U. Caffeine and anxiety. Appetite. 2006;47:274.

76. Nardi AE, Lopes FL, Valença AM, et al. Caffeine challenge test in panic disorder and depression with panic attacks. Compr Psychiatry. 2007;48:257-263.

77. Nardi AE, Lopes FL, Freire RC. Panic disorder and social anxiety disorder subtypes in a caffeine challenge test. Psychiatry Res. 2009; 169:149-153.

78. McCurry SAM, Logsdon RG, Teri L, Vitiello MV. Evidence-based psychological treatments for insomnia in older adults. Psychol Aging. 2007;22:18-27.

79. Bélanger L, LeBlanc M, Morin CM. Cognitive behavioral therapy for insomnia in older adults. Cogn Behav Pract. 2012;19:101-115.

80. Fiorentino L, Martin JL. Awake at $4 \mathrm{am}$ : treatment of insomnia with early morning awakenings among older adults. J Clin Psychol. 2010; 66:1161-1174.

81. Tremblay V. Facteurs spécifiques et non spécifiques prédisant l'effet de la thérapie cognitivo-comportementale de l'insomnie chronique comorbide au cancer du sein [unpublished doctoral dissertation]. Laval University; 2008. Available from: http://www.theses.ulaval. ca/2008/25628/25628.pdf.

\section{Dovepress}

original research, clinical \& epidemiological studies, reviews \& evaluations, case reports and extended reports. The manuscript management system is completely online and includes a very quick and fair peerreview system, which is all easy to use. Visit http://www.dovepress.com/ testimonials.php to read real quotes from published authors. 